\title{
Evaluation of the Perception of Group Therapy in Mothers with Postnatal Depression
}

\section{Anne-Catherine Rolland ${ }^{\star}$ and Clémence Lefebvre-Chanson}

Service de psychothérapie de l'enfant et de l'adolescent, Pôle Femme-Parents-Enfant, Centre Hospitalier Universitaire, Av du Gl Koenig, France

\section{Abstract}

Backgrounds: Postnatal depression (PND) affects 10 to $15 \%$ of women in the year after giving birth. The postnatal depression group is an innovative care device, a group therapy for mothers suffering PND, setup in 2008 by some professionals of a child psychiatry ward. The objective of the study was to evaluate the feelings of mothers with PND towards group therapy in order to assess the results and improve its delivery and quality.

Patients and method: The study sample included nine mothers who participated in the PND group over the last six years. This is a qualitative study based on a semi-structured interview using a questionnaire.

Results and discussion: All interviewed mothers were very satisfied with the group care and had a very positive overall feeling. Symptomatic improvement was particularly shown by removal of guilt, resocialization, and a renewed feeling of self-worth. The results highlight the importance of dialogue between a couple leading to an improved relationship with the partner. Group psychotherapy allows participants to discuss an emotionally intense experience with the progressive construction of a narrative in a contained and supportive space where putting it into words is possible.

Conclusion: Taking into account the methodological limitations and characteristics of the study (small study sample, interview carried out over different timelines), the results of this preliminary study are promising and this therapeutic device would merit further development.

\section{Introduction}

\section{Postnatal depression}

Postnatal depression (PND) typically begins in the first 4-6 weeks post-delivery [1,2]. Often misunderstood by close family and not easily identified by medical or paramedical professionals, PND is estimated to affect 10 to $15 \%$ of mothers $[1,3,4]$. Two peaks in the frequency of PND have been observed: towards the sixth week and thereafter between the ninth and fifteenth month post-partum $[5,6]$.

Fatigue, along with extremely demanding child care, remain the most common, rational, and reassuring explanation for everyone, including the mother, who does not let herself think about it or say that she is not doing well, due to a heavy cultural pressure to see childbirth as a necessarily happy event. According to Philippe Jeammet and Nicole Guedeney [7], self-censorship is common in postnatal depression.

PND symptomology is characterized by almost daily and usually hidden weeping, feeling of exhaustion, emotional lability, irritability sometimes manifested as aggression generally directed towards the spouse, along with anhedonia in daily tasks centered on the baby. Psychomotor retardation is not very noticeable; indeed, on the contrary, a state of slight sub-agitation may appear. Low self-esteem is centered on the inability to satisfy the baby's needs and focusing on maternal anxiety, with a permanent feeling of guilt from not being able to cope with the situation [1]. Finally, there is impulsion phobia characterized by an obsessive fear of committing acts which may lead to the death of the newborn.

The quality of the first mother-baby interactions is considered essential for the psychological development of the child. Winnicott suggested the essential role of the environment in the genesis of the child's affective development, stating that it is the mother who establishes the infant's mental health while she is preoccupied with looking after her newborn [8].
One of the semiological peculiarities of PND is that it is known to have a negative impact on the child's development [9-11]. PND can affect the quality of mother-baby interactions [12], particularly PND which is associated with other risk factors and personal history of depression, antenatal depression, even personality disorder elements, which are the most harmful to the quality of the interactions and the development of the infant [13].

The objective of our study was to evaluate the perception of the mothers towards this singular care, that is, the group called postnatal depression group, through a semi-structured interview in order to assess the results and improve its delivery and its quality.

\section{Presentation of the care proposed}

The postnatal depression group is a care device for mothers suffering from PND, developed by some professionals of the child psychiatry ward in 2008. This innovative device is integrated with a unit offering psychological care in perinatally for children (under 3 years) and their parents at the Women-Parents-Children department of Reims' University Hospital Centre. Its origin is Prof. Rolland's academic mobility in the service of Prof. Jeannette Milgrom in Melbourne [14]. Jeannette Milgrom developed a cognitive behavioral therapy (CBT) approach for postnatal depression [15].

"Corresponding Author: Prof. Anne-Catherine Rolland, Service de psychothérapie de l'enfant et de l'adolescent, Pôle Femme-Parents-Enfant, Centre Hospitalier Universitaire, Av du GI Koenig, 51092 Reims cedex, France E-mail: acrolland@chu-reims.fr

Citation: Rolland AC, Lefebvre-Chanson C (2017) Evaluation of the Perception of Group Therapy in Mothers with Postnatal Depression. Int J Pediatr Neonat Care 2: 129. doi: https://doi.org/10.15344/2455-2364/2017/129

Copyright: (c) 2017 Rolland et al. This is an open-access article distributed under the terms of the Creative Commons Attribution License, which permits unrestricted use, distribution, and reproduction in any medium, provided the original author and source are credited. 
Several studies have evaluated the effectiveness of psychotherapies and in particular, cognitive behavioral therapies for treating depressive disorders and have shown a comparable or higher degree of effectiveness in major depressive episodes to that of antidepressants when it comes to symptomatic improvement or remission of the current episode [16-18].

The group care offered in child psychiatry ward is partly based on the Australian model, but by following a psychodynamic model while taking into account the systemic aspect with the genogram.

Ten weekly sessions are planned at fixed times, with two further sessions being included with the fathers (therefore 12 sessions in total). For several years, three remote sessions have been proposed within four to six months after the group therapy has come to an end. The question regarding time limitation is important. Defining the precise duration of the therapy at the start contributes to a change being triggered and allows adherence (for example, in our case by allowing the planning to take place within return to work). With regard to the number of sessions, we based this on the group therapy approach by Jeannette Milgrom which proposes structured group sessions over a period of 9 weeks. Some authors [19] state that very early therapy is essential, around the 4 th/6th week post-partum, for a period of 3 to 4 months.

The group is aimed at women on their own, without their children, but they are given theoption to bring their children along. The children are gathered in a room designed for little tots to be taken care of by an infancy professional in our department (nursery nurse) and a medical student. This offer has been well received by the mothers who express their interest in having a space just for themselves where in they exist as women and not just as mothers. However, certain perinatal group therapies include babies as group participants, basing their decision on the effects of their presence in joint mother-baby therapies [20]. This is a closed group, with a minimum of three patients and a maximum of five. The group is facilitated by two therapists present at each session. With the sessions being filmed, a third professional observes the session live in the adjacent recording room, allowing a view from outside on the situations. The group always meets at the same place, enabling unity with respect to place for the group. The framework for the group is explained to the mothers in a prior individual interview: the regularity of attendance, free expression, the discretion rule meaning the confidentiality of the statements and narratives shared within the group situation.

In each session, a broad theme for discussion is predefined and announced in the previous session (for example the desire for a child, pregnancy, delivery, returning home, family, etc.). This allows the mothers to initiate the exchanges more easily while at the same time not limiting them. Spontaneous dialogue and free associations are encouraged.

\section{Material and Method}

\section{Study group}

This study examined mothers who participated in the postnatal depression group in the last few years at the Reims CHU child psychiatry ward. From each of the nine groups formed between 2012 and 2015, nine mothers chosen at random were contacted (one per group), and they were offered an individual interview. Of these nine mothers, seven accepted without any particular problem, one had moved to another region, and one did not respond to our messages. Two other mothers were chosen at random for the 2 groups concerned, and they both agreed to participate in our study.

Our study group comprised nine mothers who participated in a PND group therapy between 2010 and 2015. None of these mothers had participated in the group therapy at the same time. The analysis of the group characteristics showed the average age to be 27 years. They were all married or living with the baby's father, except one mother who cohabited with a female partner. Eight mothers were primiparous when they received PND care. All participants completed a screening scale, the Edinburgh Postnatal Depression Scale (EPDS) [21]. Fora score higher than or equal to 11, a diagnosis of postnatal depression was confirmed by a psychiatrist before the group therapy started.

\section{Methodological procedure and tools}

We explored the perception of group therapy among the nine mothers with postnatal depression.

We opted for a semi-structured interview, done by an outside psychiatrist at the unit and taken place in another hospital, to examine the perceptions of the mothers on the group therapy because it allowed us to establish a more direct relationship with the mother by modulating the questions in the most appropriate manner for each case. The questionnaire used for the semi-structured interview (see Annex 1) is partly based on the interview of maternal representations during pregnancy (IRMAG) [2].

The global perception was represented using a visual analogue scale (VAS) from 0 to 5 (from very negative to very positive).

\section{Results}

\section{What was your first reaction when you were offered group therapy?}

Four mothers immediately responded positively, because they were ready to try anything, feeling so bad, with a need to take away the feeling of guilt by meeting other mothers. The others stated that they were more reserved.

\section{Did you have any prior concerns about this type of therapy?}

The mothers raised issues such as being classified as ill, visiting the $\mathrm{CHU}$, the fear of constraints linked to the weekly pattern, the fact that it would be filmed, the fear of not daring to express themselves, and the fear of meeting mothers who were doing even worse and being dragged down. Four mothers did not have any prior concerns about this type of therapy.

\section{Did you already have the experience of a group therapy?}

None of the mothers had any such experience.

In your opinion, what were the benefits of group therapy compared to individual therapy?

Not feeling alone anymore and not just being with a doctor was the primary benefit of the group therapy. For all mothers, notions such as mutual support, solidarity, sharing experiences were revealed during the interviews, as well as feeling less guilty and having a renewed sense of self-worth. 
Citation: Rolland AC, Lefebvre-Chanson C (2017) Evaluation of the Perception of Group Therapy in Mothers with Postnatal Depression. Int J Pediatr Neonat Care 2: 129. doi: https://doi.org/10.15344/2455-2364/2017/129

Page 3 of 5

Did you encounter any difficulties during the group therapy?

Two mothers reported difficulties including turn-taking, intense emotional release, and an imbalance of talking time between mothers, which could sometimes have been redressed by the therapists. Two mothers did not encounter any particular difficulties.

\section{What do you think about the number of sessions?}

Most women had preferred 2 or 3 additional sessions, and had an unfinished feeling.

\section{What do you think about the topics discussed?}

All mothers stated complete, and all of them described themselves as feeling satisfied with the topics discussed. One mother highlighted the positive aspect of speaking freely, without being restricted, about one specific topic per session.

\section{How did you find the two sessions with the fathers?}

For one of the mothers, these sessions were not offered and that was something missing from the therapy. Other mothers stated, the sessions were too short, and at least one more needed to be added. The sessions were well received that highlighted emotionally powerful sessions, which allowed fathers to realize that other couples were in the same boat, and mothers to see their husbands from another perspective.

In your opinion, what was the effect of this experienceon your partner and your relationship?

The experience was described as a new way of communicating and a more open dialogue between the couple. A reassuring effect, his wife not being alone and other people living through the same thing were considered as positive impact on the partner. One mother emphasized how she viewed her husband after hearing him say things he had never expressed.

\section{What relationship did you establish with other mothers?}

Most mothers expressed pleasant meetings, creating strong ties, special ties, shared pleasure of meeting during the weekend, sharing experiences, and developing a bond of trust as if we had always known each other.

\section{Did you talk about the group therapy to the people around you?}

Six mothers answered yes, no shame, and wanting people to be aware of PND. Other mothers expressed feeling of shame and being isolated, which were concomitant to their state.

How did you find the last session and the group therapycoming to an end?

Sadness, longing, feeling of fear of the post-group therapy were expressed; one mother highlighted the importance of knowing that they could call the department even after the group therapy had ended. The ending was expressed by three mothers as frustrating end because the therapy only lasted for a short while.
What do you think about sessions taking place 2 to 3 months after the group therapy has ended?

Importance of taking stock for the group as well as for the individual, allowing them to observe the progress compared to how they were before.

One of the mothers realized that the work was not finished and these sessions allowed the therapy to begin again.

\section{Did you pursue individual therapy?}

Two mothers did not seek individual follow-up after the group therapy, but stated that they presently felt the need for it.

Are you currently taking psychotropic drug therapy such as antidepressants or anxiolytics?

Two mothers answered yes (antidepressants in monotherapy).

\section{Did the group therapy meet your expectations?}

All mothers answered yes.

With regard to this therapy, what is your overall feeling? (Score from 0 to 5 ).

All mothers evaluated the overall feeling as 5 (very positive).

We have discussed your experience and your perception of the group therapy; are there anypositive or negative aspects that we have not discussed?

Regarding positive aspects, the common significant elements were

1. the possibility of having the baby looked after by someone from the team (1 mother);

2. the few number of participants in having a small group effect and allowing enough time for each mother to talk (1 mother);

3. the contact with kind, human, and friendly therapists (3 mothers);

4. being able to speak freely (1 mother);

5. the chance to step out of her isolation (1 mother);

6. a very positive experience without any negative aspects (2 mothers).

Regarding negative aspects, the common significant elements were

1. the lack of a remote evaluation meeting ( 3 mothers);

2. talking time not shared fairly between the mothers: give everyone a chance to express themselves ( 2 mothers);

3. the lack of negative aspects for 2 mothers.

\section{Discussion}

The shared situation of the small group allows for specific psychological processes to be activated which transcend individual effects, and the participants of which are conscious or unconscious agents, and beneficiaries. 
According to Kaës, the group designs refer to the paradigmatic form and structure of an organization with inter-subjective links, under the appearance where the relationships between several subjects of the unconscious produce specific psychological processes and formations [22]. Anzieu, in the moi-peau (skin-Ego) metaphor, proposed the group envelope concept as follows: a group is an envelope which keeps all the individuals inside [23]. The group moi-peau contains, defines, and protects, and because it remains permeable, it allows exchanges with the outside world. The group envelope allows for the establishment of a transindividual psychic state for which Anzieu proposed the name of a group self: the group has a specific and imaginary self. It is from being contained inside that a fantastical and identifying circulation is activated among the people. This is what makes the group alive [23]. The group, through its contained, safe function, provides a support for the faulty counter-excitement functions. The need to belong represents a fundamental human need. The subject invests in a group from which they ask in exchange the guarantee of his/her place and to be provided with a set of potential identifying features. Working on the group, on its constitution as a space with an inside and an outside, is to participate in a movement establishing a limiting envelope which allows for a place of ideas, an area of symbolization, to be prepared. The idea is that, from the group, each individual has internalized the group resources, and the group solution becomes an individual solution.

The group dynamic appears to bear a lot of weight, and issues which seem individual at the outset, seem to be faced, confronted, and made sense of by everyone.

\section{Study Limitations}

The evaluation interviews for the nine mothers were carried out at different points in time with respect to the group therapy ending. All mothers in the study group had received a diagnosis of postnatal depression, but the severity of the episode for each mother was not evaluated. Although one mother from each group was chosen at random to be interviewed, the generalizability of the findings is questionable, and the study sample was very small. The fathers were not interviewed about their perception of this care device. However, the limitations of any qualitative study should be considered.

\section{Conclusion}

The results of our study are promising; all the mothers were satisfied with the group therapy in its different aspects, with a very positive feeling towards it.

Providing treatment to depressed mothers through group therapy allows young mothers to understand other women in difficulties, which resonates with their own difficulties, it makes them relieved, and helps them express their emotions through a feeling of support and strong identification.

Most of the mothers emphasized how PND is misunderstood by people around them-not only family and friends but also medical and paramedical personnel-with a lack of detection of PND by healthcare professionals. It is regrettable that many women remain trapped in their difficulty due to a lack of screening.

Annex 1: Questionnaire used for the semi-directed interview regarding the evaluation of feelings toward group therapy for women with postnatal depression
1. What was your first reaction when you were offered group therapy?

2. Did you have any prior experience of this type of therapy?

3. Did you already have any experience of a group?

4. In your opinion, what were the benefits of group therapy compared to individual therapy?

5. Did you encounter any difficulties during the group therapy?

6. What do you think about the number of sessions?

7. What do you think about the topics discussed?

8. How did you find the sessions with the fathers?

9. In your opinion, what was the effect of this experience on your partner and your relationship?

10. What relationship did you establish with the other mothers?

11. Did you talk about the group therapyto the people around you?

12. How did you find the last session and the group therapy coming to an end?

13. What do you think about sessions taking place 2 to 3 months after the group therapy has ended?

14. Did you pursue individual therapy?

15. Are you currently taking psychotropic drug therapy such as antidepressants or anxiolytics?

16. Did the group therapy meet your expectations?

17. With regard to this therapy, what is your overall feeling? (Score from 0 to 5)(Figure 1)

\begin{tabular}{|c|c|c|c|c|c|c|c|c|c|c|}
\hline \multicolumn{11}{|c|}{ Thanks to note your feelings about this therapy II } \\
\hline 0 & $\rightarrow$ & 1 & $\rightarrow$ & 2 & $\rightarrow$ & 3 & $\rightarrow$ & 4 & $\rightarrow$ & 5 \\
\hline গ & & & & & & & & & & \\
\hline $\begin{array}{l}\text { Very } \\
\text { negative } \\
\text { ๆ }\end{array}$ & $\vec{\rightarrow}$ & $\underset{\rightarrow}{\text { negative }}$ & $\rightarrow$ & $\begin{array}{l}\text { rather } \\
\text { negative }\end{array}$ & $\vec{\rightarrow}$ & $\begin{array}{l}\text { rather } \\
\text { positive }\end{array}$ & $\rightarrow$ & $\underset{\rightarrow}{\text { sitive }}$ & $\rightarrow$ & $\begin{array}{l}\text { very } \\
\text { positive? }\end{array}$ \\
\hline
\end{tabular}

Figure 1: Overall felling score from 0 to 5.

18. We have discussed your experience and feelings about the group therapy; are there any positive or negative aspects that we have not discussed?

\section{Competing Interests}

The authors declare that they have no competing interests.

\section{Author Contributions}

Lefebvre-Chanson/CLC \& Rolland/ACR performed the literature and conceived the initial protocol. Lefebvre-Chanson/CLC interviewed the mothers. Rolland/ACR \& Lefebvre-Chanson/CLC wrote the paper.

\section{Acknowledgements}

We wish to thank the therapists who led the different groups, the nursery nurses, and the students who looked after the children, and of course, all mothers who actively participated in this study.

\section{References}

1. Agbokou C, Ferreri F, Nuss P, Peretti CS (2011) Cliniques des dépressions maternelles postnatales. EMC 1-7.

2. Ammaniti M, Candelori C, Pola M, Tambelli R (1999) Maternité et grossesse: étude des représentations maternelle. Paris: Presses Universitaires de France. 
Citation: Rolland AC, Lefebvre-Chanson C (2017) Evaluation of the Perception of Group Therapy in Mothers with Postnatal Depression. Int J Pediatr Neonat Care 2: 129. doi: https://doi.org/10.15344/2455-2364/2017/129

Page 5 of 5

3. O'Hora MW, Swain AM (1996) Rates and risks of postpartum depression. A meta-analysis. Int Rev Psychiatry 8: 37-54.

4. Segre LS, O'Hara MW, Arndt S, Stuart S (2007) The prevalence of postpartum depression: the relative significance of three social status indices. Soc Psychiatry Psychiatr Epidemiol 42: 316-321.

5. Pop VJ, Essed GG, De Geus CA, Van Son MM, Komproe IH, et al. (1993) Prevalence of postpartum depression - or is it post-puerperium depression? Acta Obstet Gynecol Scand. 72: 354-358.

6. Holt WJ (1995) The detection of postnatal depression in general practice using the Edinburgh postnatal depression scale. N Z Med J 108: 57-59.

7. Guedeney N, Jeammet $P$ (2001) Dépressions post natales (DPN) et décisions d'orientation thérapeutique. Devenir 13: 51-64.

8. Winnicott DW (1984) Through Paediatrics to Psychoanalysis: Collected Papers. London : Karnac 300-305.

9. Murray L, Cooper PJ (1997) Effects of postnatal depression on infant development. Arch Dis Child 77: 99-101.

10. Prenoveau JM, Craske MG, West V, Giannakakis A, Zioga M, et al. (2017) Maternal postnatal depression and anxiety and their association with child emotional negativity and behavior problems at two years. Dev Psychol. Jan 53: 50-62.

11. Kawai E, Takagai S, Takei N, Itoh H, Kanayama N, et al. (2017) Maternal postpartum depressive symptoms predict delay in non-verba communication in 14-month-old infants. Infant Behav Dev. Fev 46: 33-45.

12. Granat A, Gadassi R, Gilboa-Schechtman E, Feldman R (2017) Maternal depression and anxiety, social synchrony, and infant regulation of negative and positive emotions. Emotion 17: 11-27.

13. Guyon-Harris K, Huth-Bocks A, Lauterbach D, Janisse H (2016) Trajectories of maternal depressive symptoms across the birth of a child: associations with toddler emotional development. Arch Womens Ment Health. Feb 19 153-165.

14. Milgrom J, Rolland AC (2008) Traitement comportemental et cognitif de la dépression du post-partum. Les dépressions périnatales : évaluer et traiter. Issy-les-Moulineaux : Elsevier Masson 88-116.

15. Meager I, Milgrom J (1996) Group treatment for postpartum depression: a pilot study. Aust N Z J Psychiatry 30: 852-860.

16. Letourneau NL, Dennis CL, Cosic N, Linder J (2017) The effects of perinatal depression treatment for mothers on parenting and child development: a systematic review. Depress Anxiety 34: 928-966.

17. Van Lieshout RJ, Yang L, Haber E, Ferro MA (2017) Evaluating the effectiveness of a brief group cognitive behavioural therapy intervention for perinatal depression. Arch Womens Mental Health 20: 225-228.

18. Scope A, Leaviss J, Kaltenthaler E, Parry G, Sutcliffe P, et al. (2013) Is group cognitive behaviour therapy for postnatal depression evidencebased practice? A systematic review. BMC Psychiatry 13: 321.

19. Nanzer N, Sancho Rossignol A, Righetti-Veltema M, Knauer D, Manzano $\mathrm{J}$, et al. (2012) Effects of a brief psychoanalytic intervention for perinatal depression. Arch Womens Ment Health 15: 259-268.

20. Pedrina $F$ (2006) Thérapie de groupe pour des mères en état de crise dans le post-partum et leurs bébés. [auteur du livre] M. Dugnat. Les émotions (autour) du bébé. Toulouse : ERES « Hors collection 239-48.

21. Cox J, Holden J, Sagovsky R (1987) Detection of post natal depression: development of the 10-item EPDS. British Journal of Psychiatry 150: 782786.

22. Kaës R (1999) Les théories psychanalytiques du groupe. Paris: Presses Universitaires de France.

23. Anzieu D (1985) Le groupe et l'inconscient. L'imaginaire groupal. Paris: Dunod. 